\title{
Treatment of sacrococcygeal pilonidal sinus
}

\section{disease in children: A systematic review and}

\section{meta-analysis}

Hardy EJO ${ }^{1,2}$, Herrod PJJ', ${ }^{1,2}$, Sian $\mathrm{T}^{1,2}$, Boyd-Carson $\mathrm{H}^{1,2}$, Blackwell JEM ${ }^{1,2}$, Lund JN ${ }^{1,2}$, Quarmby JW ${ }^{1}$

1. Department of General Surgery, Royal Derby Hospital, Derby, UK DE22 3NE2.

2. Department of Surgery, Division of Medical Sciences and Graduate Entry Medicine, University of Nottingham, Derby, DE22 2DT

Funding: This research did not receive any specific grant from funding agencies in the public, commercial, or not-for-profit sectors.

Conflicts of interest: None

Correspondence to:

Mr E Hardy

Department of Surgery,

Royal Derby Hospital,

Derby,

United Kingdom,

DE22 3NE

$(+44) 01332724905$

edward.hardy@nhs.net

Abstract Word Count: 200

Word Count: 2475

Number of figures: 1

Number of supplementary digital content files: 0 


\section{Abstract}

\section{Background / Purpose}

Sacrococcygeal pilonidal sinus disease (PSD) has an incidence of 1.2-2.5/1000 in children. Onset is around puberty. Symptoms of recurrent abscess and chronic suppuration may interfere with education and social integration. Treatments should cause minimal disruption whilst having good cure and recurrence rates. Curettage and Fibrin glue obliteration (FGO) shows promising results in adults. We present our experience of its use in children.

\section{Methods}

Review of all paediatric patients receiving FGO of pilonidal sinus performed by a single surgeon from September 2014 to February 2018.

\section{Results}

Eighteen patients identified. Median age was 16 (range 15-17), 55.6\% were male. All procedures completed as day cases. Median operative duration was 14.1 (6-29) minutes. Twelve patients required only 1 procedure, 4 required 2 procedures, 1 required 5 procedures and 1 elected for formal excision after 2 FGO treatments. Median return to normal activities was 3 days, with 1 day school absence. Two patients developed minor surgical site infections. Median follow-up was 52 weeks (17-102), during which time there was 1 recurrence (5.6\%).

\section{Conclusion}

This study demonstrates FGO is a safe, effective procedure for paediatric PNS, with results comparable to off-midline flap techniques and without the need for extensive tissue excision and the associated morbidity.

\section{KEYWORDS}

Pilonidal, Paediatric, Children, Glue, Outcomes, Surgery 
Level of Evidence rating: IV 


\section{Introduction}

Sacrococcygeal pilonidal sinus disease $\left(\mathrm{PSD}^{1}\right)$ is not uncommon in the paediatric age group with an incidence of 1.2-2.5 /1000)[1,2]. Onset is usually around the time of puberty and the symptoms of recurrent acute abscess and chronic suppuration may interfere with education and development of social integration[2,3]. Treatments for this condition should cause minimal disruption or discomfort to the patient whilst having good cure and recurrence rates.

For many years the aetiology of PSD was thought to be congenital [4-7] and traditional surgical techniques therefore involve wide excision of tissue around the PSD. This leaves large defects[3] which may be left to heal by secondary intention, marsupialised, or closed [8-10]. Healing by secondary intention, although with the lowest long term recurrence rates in meta-analysis of adult patients[11], requires long healing times (median 60-70 days), often daily dressing and discomfort for the patient. Midline primary closure is associated with high rates of breakdown and recurrence $[8,10]$. Variations of off midline closure and "cleft lift" procedures including Karydakis[12], Bascom[13], rhomboid $[14,15]$ and other advancement flaps[10] have been developed. Whilst these procedures are associated with lower rates of infection and recurrence than primary midline closure $[1,8,10,16]$, they still involve significant tissue loss, often a few days in hospital [2] and a long time (14-23 days) until return to normal activities $[17,18]$. There is as yet no ideal treatment and the choice of procedure is often determined by surgeon experience [19].

More recently there has been a general acceptance of an acquired aetiology for PSD, and it is now thought pilonidal sinuses are caused by inflamed hair follicles in the natal cleft $[4,20,21]$ or foreign body reactions to loose hairs which have become embedded in the skin [12,21]. Indeed recent electron microscopy studies have demonstrated the majority of hairs found within the sinus are rootless hairs originating from the occiput $[22,23]$. Without the need to widely excise the tissue new,

\footnotetext{
${ }^{1}$ Abbreviations: PNS - Pilonidal Sinus, FGO - Fibrin Glue Obliteration
} 
minimally invasive techniques have been developed. These include minimal excision [24], endoscopic[25], laser[10] and even non-surgical techniques[26].

Our group first described the use of fibrin glue as monotherapy for PSD in 2005 [27]. Since then this technique has been shown to have recurrence rates comparable to flap repair[28], quick recovery times and high patient satisfaction in the adult population[29]. An effective treatment with a rapid return to full activity is even more important in a paediatric age group, where disruption of school, social and sporting activities should be kept to a minimum.

We present our early experience of the use of FGO in paediatric pilonidal sinus disease.

\section{Method}

\subsection{Patient selection and identification}

Retrospective review of all paediatric patients (aged $<18$ ) undergoing FGO of pilonidal sinus performed by a single surgeon (JWQ) from September 2014 to February 2018. This time period includes all FGO procedures completed by this surgeon. Patients were identified from the theatre records, and the consultant's diary, and electronic case notes of identified patients were reviewed. Data points recorded were age, sex, operative time, length of hospital stay, number of pilonidal pits identified at surgery, number of treatments required and complications. There was no missing data. Post-operative complications were categorised according to the Clavidien-Dindo system[30].

All patients presenting with symptomatic PSD (chronic suppuration, occasional weeping, or incomplete healing following acute incision and drainage) to the operating surgeon during the study period were included. Although other treatment modalities were considered all patients were deemed suitable for FGO, and agreeable to trying this technique. 


\subsection{Operative technique}

The technique was the same as that previously described for FGO in adult pilonidal disease $[27,29]$. In brief, under general anaesthetic the pilonidal sinus complex (including all secondary tracts) was meticulously curreted with a small Volkmann's spoon, after which the pit and tract are completely filled with Fibrin glue (TISSEAL ${ }^{\mathrm{TM}}$ Baxter, Illinois, USA). Antibiotic prophylaxis was not given. Patients were followed-up at 6-8 weeks, and if there was evidence of residual disease, a discussion regarding treatment options took place and patients booked for a repeat procedure if they wished.

\subsection{Statistical Analysis}

Statistical analysis was performed using GraphPad Prism (Version 7.02, GraphPad Software, CA, USA). Data was tested for normality using the Shapiro-Wilks test. Normally distributed data reported as mean (SD), and non-parametric data as median (IQR). Non- parametric data was tested for significance using the Mann Whitney test with significance set at the $p=0.05$ level.

\section{Results}

Eighteen patients were identified during the study period. Median (range) age was 16 (15-17) years and 10/18 were male. All patients had symptomatic pilonidal sinus disease and 3 had had previous incision and drainage for an acute pilonidal abscess. At presentation 14 patients had 1 pit, 3 patients had 2 pits, 7 patients had 3 pits and 2 patients had 4 pits. All patients had Type III PNS disease according to the Navicular area concept [31]. Median (range) follow-up was 52 (17-102) weeks.

Median operative time was 12.5 minutes (10-17) and mean theatre time was 33.3 minutes ( \pm 7.57$)$. All patients were discharged on the same day as the procedure. All patients had their procedure on a Friday and were advised to return to school the following Monday, resulting in a median return to normal activities of 3 days, and a median of just 1 day of lost school attendance. 
Twenty-six procedures were completed, with a median of 1 (range 1-5) procedures per patient. Overall, 17/18 (94.4\%) patients were cured using fibrin glue alone. Twelve patients (66.7\%) were cured after 1 procedure, 4 patients (22.2\%) required a second procedure and 1 patient (5.6\%) required five procedures. Only 1 patient chose to have an intervention other than with glue, and was cured following wide excision and healing by secondary intention following persistent symptoms after 2 FGO procedures.

Patients requiring repeated procedures to achieve cure using fibrin glue had a median of 3 (1-3) pits, whereas those cured after only 1 treatment had a median of $1(1-2)$ pits $(p=0.005)$. For $4(66.7 \%)$ of the 6 patients who went on to have repeated FGO, the likely need for further procedures was predicted and formally documented in the first operation note. This suggests that the likelihood of patients requiring more than $1 \mathrm{FGO}$ can be accurately predicted from the outset.

Two patients (11.1\%) presented with surgical site infections postoperatively which were treated with oral antibiotics alone (Clavien-Dindo II).

One patient (5.6\%) presented with recurrence at 12 months, having previously been discharged after just 1 fibrin glue procedure, and is awaiting a repeat FGO.

\section{Discussion}

We have shown that FGO is a promising treatment for PSD in children. Nearly $95 \%$ of patients were successfully treated using FGO alone, with $2 / 3$ healed after only 1 treatment. Recurrences can be effectively treated with further FGO. Complications were infrequent and minor.

These results are similar to those reported in a small trial using fibrin glue in children[32] with PSD versus excisional techniques, where pit excision and fibrin glue was found to be quicker to perform, and at least as effective as lateralizing flap procedures[32]. These results are also very similar to a 5 year experience in adult PSD recently reported by our group, with $2 / 3$ healing after the first treatment 
and over 95\% healing with FGO alone[33]. Recurrence rates were low and comparable to those for off midline repairs in adults[8,10]. The one patient who required 5 courses of treatment had very extensive and complicated disease, the excision of which would have created a very significant defect. Instead, he required no excision at all and at 12 months has no evidence of recurrence.

Smith et al[32] also commented on the minimal 'social and educational disruption' associated with the glue technique, mirroring rapid return to normal seen in adults [29]. All patients in our cohort had their procedure on a Friday and returned to school the following Monday, resulting in a median return to normal activity of 3 days and just 1 day of school absence. This is important in the pubertal age group who are at critical stages of education and assessment when they develop PSD. Primary closure techniques require an average of 10-15 days for full activities to be resumed whilst wide excision and healing by secondary intention requires $18-28$ days [8]. Infective complications of primary closure techniques often require removal of sutures and packing, making time to recovery similar to wide excision in the 5-13\% who suffer this complication[8]. Treatment for PSD should not be worse than the disease itself [18].

All operations were performed in less than 30 minutes (similar to times reported by Smith et al) and all procedures were done as day cases

Repeated glue treatments did not interfere with the traditional surgical approach used in the 1 patient who required a second line treatment. It therefore seems acceptable to try repeat FGO for recurrence, as many heal and all other excisional options, with or without primary flap closure, are still available if required.

Of note, the number of midline pits was significantly associated with the need for multiple procedures $(p<0.01)$ but it is not known whether the number of pits per se affects the severity of disease, and it may be volume of the pilonidal complex or length of the tracts which is an important consideration. All patients had the same navicular classification[31], and it may be that this anatomical classification of PSD is not helpful for stratifying and personalising treatment. It is likely that early recurrence is due 
to retention of debris despite meticulous curettage, and late recurrence is true recurrence of disease, with reimplantation of loose hairs in the natal cleft.

\subsection{Limitations}

We report a relatively small series of patients. Length of follow up is limited (some authors suggesting that up to 20 year follow up is required to state that PSD is truly healed[34]) and it is known that recurrence increases with time [10]. Longer term follow up is required by this and most other studies in the paediatric and adult PSD literature to establish true, long term outcomes.

Large, multicentre trails of fibrin glue compared to other treatments are awaited in adults, and will evaluate quality of life, cost and factors important to patients when choosing PSD treatment, as well as the more obvious surgical outcomes. Similar studies would be helpful in children.

\section{Conclusion}

Curettage and fibrin glue obliteration of pilonidal sinus is a safe and effective procedure in children, and shows promise as a first line approach for most patients with this condition. 


\section{References}

[1] Nasr A, Ein SH. A pediatric surgeon's 35-year experience with pilonidal disease in a Canadian children's hospital. Can J Surg 2011;54:39-42. doi:10.1503/cjs.028509.

[2] Fike FB, Mortellaro VE, Juang D, Ostlie DJ, St. Peter SD. Experience with Pilonidal Disease in Children. J Surg Res 2011;170:165-8. doi:10.1016/J.JSS.2011.02.016.

[3] Allen-Mersh G, Allen-Mersh TG. Pilonidal sinus: finding the right track for treatment 1990;77:12-132.

[4] Chamberlain JW, Vawter GF. The congenital origin of pilonidal sinus. J Pediatr Surg 1974;9:441-4. doi:10.1016/S0022-3468(74)80001-1.

[5] Haworth JC, Zachary RB. CONGENITAL DERMAL SINUSES IN CHILDREN THEIR RELATION TO PILONIDAL SINUSES. Lancet 1955;266:10-4. doi:10.1016/S0140-6736(55)93376-6.

[6] da Silva JH. Pilonidal cyst: cause and treatment. Dis Colon Rectum 2000;43:1146-56.

[7] RAFFMAN RA. A re-evaluation of the pathogenesis of pilonidal sinus. Ann Surg 1959;150:895903.

[8] McCallum IJD, King PM, Bruce J. Healing by primary closure versus open healing after surgery for pilonidal sinus: systematic review and meta-analysis. BMJ 2008;336:868-71. doi:10.1136/bmj.39517.808160.BE.

[9] Yoldas T, Karaca C, Unalp O, Uguz A, Caliskan C, Akgun E, et al. Recurrent pilonidal sinus: lay open or flap closure, does it differ? Int Surg 2013;98:319-23. doi:10.9738/INTSURG-D-1300081.1.

[10] Stauffer VK, Luedi MM, Kauf P, Schmid M, Diekmann M, Wieferich K, et al. Common surgical procedures in pilonidal sinus disease: A meta-analysis, merged data analysis, and comprehensive study on recurrence. Sci Rep 2018;8:3058. doi:10.1038/s41598-018-20143-4. 
[11] AL-Khamis A, McCallum I, King PM, Bruce J. Healing by primary versus secondary intention after surgical treatment for pilonidal sinus. Cochrane Database Syst Rev 2010. doi:10.1002/14651858.CD006213.pub3.

[12] Karydakis GE. NEW APPROACH TO THE PROBLEM OF PILONIDAL SINUS. Lancet 1973;302:1414-5. doi:10.1016/S0140-6736(73)92803-1.

[13] Bascom J, Bascom T. Failed pilonidal surgery: new paradigm and new operation leading to cures. Arch Surg 2002;137:1146-50; discussion 1151.

[14] Aithal SK, Rajan CS, Reddy N. Limberg flap for sacrococcygeal pilonidal sinus a safe and sound procedure. Indian J Surg 2013;75:298-301. doi:10.1007/s12262-012-0489-5.

[15] Lieto E, Castellano P, Pinto M, Zamboli A, Pignatelli C, Galizia G. Dufourmentel Rhomboid Flap in the Radical Treatment of Primary and Recurrent Sacrococcygeal Pilonidal Disease. Dis Colon Rectum 2010;53:1061-8. doi:10.1007/DCR.0b013e3181defd25.

[16] Horwood J, Hanratty D, Chandran P, Billings P. Primary closure or rhomboid excision and Limberg flap for the management of primary sacrococcygeal pilonidal disease? A metaanalysis of randomized controlled trials n.d. doi:10.1111/j.1463-1318.2010.02473.x.

[17] H. Abu Galala, Isam M. A. Salam, Kh K, Salam IM, Abu Samaan KR, El Ashaal YI, Chandran VP, Sabastian M, et al. Treatment of Pilonidal Sinus by Primary Closure with a Transposed Rhomboid Flap Compared with Deep Suturing: a Prospective Randomised Clinical Trial. Eur J Surg 1999;165:468-72. doi:10.1080/110241599750006721.

[18] Lund JN. Less Is More in the Treatment of Pilonidal Sinus Disease. Dis Colon Rectum 2017;60:e1. doi:10.1097/DCR.0000000000000727.

[19] Can MF, Sevinc MM, Hancerliogullari O, Yilmaz M, Yagci G. Multicenter prospective randomized trial comparing modified Limberg flap transposition and Karydakis flap reconstruction in patients with sacrococcygeal pilonidal disease. Am J Surg 2010;200:318-27. 
doi:10.1016/j.amjsurg.2009.08.042.

[20] Bascom J. Pilonidal disease: origin from follicles of hairs and results of follicle removal as treatment. Surgery 1980;87:567-72.

[21] Kumar S, Haboubi N, Chintapatla S, Safarani N. Sacrococcygeal pilonidal sinus: historical review, pathological insight and surgical options. Tech Coloproctol 2003;7:3-8. doi:10.1007/s101510300001.

[22] Gosselink MP, Jenkins L, Toh JWT, Cvejic M, Kettle E, Boadle RA, et al. Scanning electron microscope imaging of pilonidal disease. Tech Coloproctol 2017;21:905-6. doi:10.1007/s10151-017-1702-0.

[23] Bosche F, Luedi MM, van der Zypen D, Moersdorf P, Krapohl B, Doll D. The Hair in the Sinus: Sharp-Ended Rootless Head Hair Fragments can be Found in Large Amounts in Pilonidal Sinus Nests. World J Surg 2018;42:567-73. doi:10.1007/s00268-017-4093-5.

[24] Speter C, Zmora O, Nadler R, Shinhar D, Bilik R. Minimal incision as a promising technique for resection of pilonidal sinus in children. J Pediatr Surg 2017;52:1484-7. doi:10.1016/J.JPEDSURG.2017.03.040.

[25] Meinero P, Stazi A, Carbone A, Fasolini F, Regusci L, La Torre M. Endoscopic pilonidal sinus treatment: a prospective multicentre trial. Color Dis 2016;18:0164-70. doi:10.1111/codi.13322.

[26] Salih AM, Kakamad FH, Salih RQ, Mohammed SH, Habibullah IJ, Hammood ZD, et al. Nonoperative management of pilonidal sinus disease: one more step toward the ideal management therapy—a randomized controlled trial. Surgery 2018. doi:10.1016/j.surg.2017.12.014.

[27] Lund JN, Leveson SH. Fibrin Glue in the Treatment of Pilonidal Sinus: Results of a Pilot Study. Dis Colon Rectum 2005;48:1094-6. doi:10.1007/s10350-004-0905-4. 
[28] Boereboom C, Watson N, Liptrot S, Lund J. A randomised trial of fibrin glue vs surgery for pilonidal sinus disease: results and long term follow up. Color Dis 2010;12:1281. doi:10.1111/j.1463-1318.2010.02336.x.

[29] Elsey E, Lund JN. Fibrin glue in the treatment for pilonidal sinus: high patient satisfaction and rapid return to normal activities. Tech Coloproctol 2013;17:101-4. doi:10.1007/s10151-0120956-9.

[30] Dindo D, Demartines N, Clavien P-A. Classification of surgical complications: a new proposal with evaluation in a cohort of 6336 patients and results of a survey. Ann Surg 2004;240:20513. doi:10.1097/01.SLA.0000133083.54934.AE.

[31] Tezel E. A new classification according to navicular area concept for sacrococcygeal pilonidal disease. Color Dis 2007;9:575-6. doi:10.1111/j.1463-1318.2007.01236.x.

[32] Smith CM, Jones A, Dass D, Murthi G, Lindley R. Early experience of the use of fibrin sealant in the management of children with pilonidal sinus disease. J Pediatr Surg 2015;50:320-2. doi:10.1016/J.JPEDSURG.2014.11.022.

[33] Sian T, Lund J. P563: Fibrin glue is a simple, quick and effective treatment of pilonidal sinus disease. Color Dis 2017;19:35-139. doi:10.1111/codi.13798.

[34] Doll D, Krueger CM, Schrank S, Dettmann H, Petersen S, Duesel W. Timeline of Recurrence After Primary and Secondary Pilonidal Sinus Surgery. Dis Colon Rectum 2007;50:1928-34. doi:10.1007/s10350-007-9031-4. 
Legends for figures

Fig1. STROBE flow diagram 